\title{
VIEWPOINT
}

\section{Coronavirus Pandemic: The Roles of Environmental Education and Conservation Message Framing in Curbing Zoonotic Diseases}

Tayo Akeem Yusuf, Lateef Lamina Memorial College, Nigeria

\begin{abstract}
This viewpoint paper posits that it is helpful to frame environmental problems as human health problems. The most fundamental way to protect ourselves from zoonotic diseases (such as COVID-19) seems to be support healthy ecosystems that have resilience. Humans around the world are sometimes motivated by selfish motives and sometimes by altrustic motives. This viewpoint paper proposes an integrative view of environmental behaviour with dimensions of both selftranscendence (altruism) and self-enhancement (egoism), in the hope that both kinds of values could lead to an increase in pro-environmental behaviour.
\end{abstract}

Keywords: pro-environmental behaviour, self-enhancement (egoism), self-transcendence (altruism), message frames, zoonotic diseases

\section{Introduction}

Along with destruction of habitats and climate change, an increasing incidence of zoonotic diseases is evident in human populations across the world. Can environmental education help to change our unsustainable practices and lead to more responsible behavioural patterns? This viewpoint paper posits that it is helpful to frame environmental problems as human health problems. The ravaging coronavirus infection may have 'jumped' from animals to humans due to the destruction of natural buffers between them. The next zoonotic disease is on the horizon if ecological habitat destruction and human induced climate change are not kept under control.

\section{A global increase in zoonotic diseases}

According to a 2016 United Nations Environment Programme (UNEP) report, on average, three new infectious diseases emerge in humans every year; $75 \%$ of these emerging infectious diseases in humans are now zoonotic (UNEP, 2020a \& 2020b). The emergence of the COVID-19 pandemic (a zoonotic disease) is at present disrupting health systems, negatively impacting the physical and mental health and well-being of societies, and causing deaths. Framing environmental actions (such as conserving natural habitats and slowing climate change) as 
promoting health behaviours should therefore be relevant, meaningful and acceptable to individuals and nations around the world, especially at this time.

Recent zoonotic disease outbreaks include Severe Acute Respiratory Syndrome or SARS (2002); Avian Influenza or Bird Flu (2004); H1N1 or Swine Flu (2009); Middle East Respiratory Syndrome or MERS (2012); Ebola (2014-2015); Zika virus (2015-2016); and the West Nile virus (2019). In addition to the current SARS-CoV-2 virus, scientists warn that there are other coronaviruses circulating in animals that have not yet infected humans (UNEP, 2020a \& 2020b).

Growing evidence suggests that outbreaks or epidemic diseases may become more frequent if we continue to destroy nature, exploit wild species and engage in actions that increase climate change (UNEP, 2020a \& 2020b). The nations of the world can either choose between marshalling medical science and technology to produce vaccines for more than 1.7 million pathogens and viruses that are capable of jumping from wildlife to infect humans, or address the underlying drivers of zoonotic diseases - destruction of nature, exploitation of wildlife species and climate change.

This viewpoint paper proposes that policy makers and environmental education practitioners should integrate message frames presenting environmental problems as personal health problems into environmental education curricula and programmes to engage a larger audience in environmental actions. Message frames can be keys for engaging a broader audience in environmental action.

\section{Environmental health message frames}

Despite the links between the environment and health, campaigns designed to promote sustainable behaviour are rarely framed in terms of human health, and strategies to change health related behaviour patterns are not often applied to environmental behaviour (Nisbet \& Gick, 2008).

Conservation message framing in terms of personal health matters should, in the author's view, ensure that:

- people personally feel greater susceptibility and severity of an environmental health risk with a less intense (weaker) cue;

- people see that the benefit of taking environmental action that is likely to prevent or reduce the personal health risk far outweighs the barriers or any obstacles that may prevent engagement in responsible or pro-environmental behaviour.

Nisbet and Gick (2008) submitted that future work by environmental educators and researchers should focus on three specific areas: increasing awareness of environmental issues, including their possible health consequences (and potential solutions); fostering positive attitudes and supporting environmental activities; and creating effective behaviour change interventions. 


\section{Altruism or egoism as motivators?}

According to Batson (2011) and Knez (2013), there are two kinds of goals that motivate people towards environmental actions: the self-transcending (altruists) have empathy-related goals (sacrifice for the environment and others) while the self-enhancing (egoists) are motivated by self-benefit goals (such as personal comfort and safety and economic benefits).

People's moral obligations regarding the environment may be selfishness or unselfishness, differentiating them into egoistic and altruistic individuals respectively (Bucciarelli, Khemlani \& Johnson-Laurd, 2008; Knez, 2016). Both egoism and altruism can play a role in proenvironmental behaviours. While the role of altruism is key for environmental education, it is proposed that policy makers and environmental education practitioners should also design and integrate message frames presenting environmental problems in terms of personal health problems in environmental education programmes and curricula, in order to engage a larger audience in environmental actions.

Many environmental education curricula are based on the approach that a self-transcending pathway will lead to positive environmental behaviour. However, in reality it is likely that more than altruism is responsible for strongly shaping and influencing environmental attitudes and values of individuals. Levy, Orion and Leshem (2016) argued that pro-environmental behaviour is driven by egoistic concerns, stressing that most environmental campaigns have failed (at least in Israel where their research was conducted) because they were based on altruistic slogans.

The dominant approach for promoting pro-environmental behaviour, to date, has focused on empathy for others or nature (De Dominicis et al., 2017). It appears that durable long-term pro-environmental behaviour requires activation of intrinsic motives (self-transcendence values) in individuals (Bolderdijk et al., 2013; Schwartz et al., 2015). Extrinsic motives such as economic interests or other financial incentives may even make people less likely to carry out environmental actions in general (Schwartz, 1992; Grouzet et al., 2005; Thøgersen \& Crompton, 2009; Evans et al., 2013).

It is proposed that an integrative approach that frames environmental problems in terms of personal health problems can be used to modify attitudes that can be self-enhancing in the service of conserving and protecting the environment.

\section{Conclusion}

COVID-19 is a reminder of the close linkage between human health and environmental health, and of the fact that humans around the world are sometimes motivated by selfish motives and sometimes by altrustic motives. The most fundamental way to protect ourselves from zoonotic diseases seems to be to prevent destruction of nature. Only ecosystems that are healthy and support a diversity of species (or are rich in biodiversity) have the reslience and integrity to regulate and reduce incidence of diseases (UNEP, 2020a).

This viewpoint paper proposes an integrative view of environmental behaviour with dimensions of both self-transcendence (altruism) and self-enhancement (egoism), in the hope 
that both kinds of values could lead to an increase in pro-environmental behaviour. In addition, appropriate message framing that presents environment problems as health problems could make individuals feel increased susceptibility and severity of health risks related to negative environment behaviour, even if such threats will occur in the long term.

The author concludes by advocating for further research on the persuasive effects of message framing in engaging a larger audience in environmental actions.

\section{Notes on the contributor}

\section{Yusuf, Tayo Akeem}

Tayo Akeem Yusuf is currently the principal and environmental education advisor at Lateef Lamina Memorial College. He has a master's in science education and has taught science and environmental education for about 26 years in Nigeria and Tanzania.

\section{References}

Batson, C. D. (2011). Altruism in Humans. New York: Oxford University Press.

Bolderdijk, J. W., Steg, L., Geller, E.S., Lehman, P.K. \& Postmes, T. (2013). Comparing the effectiveness of monetary versus moral motives in environmental campaigning. Nature Climate Change, 3, 413-416. doi: 10.1038/nclimate1767.

Bucciarelli, M., Khemlani, S. \& Johnson-Laurd, P.N. (2008). The psychology of moral reasoning. Judgment and Decision Making, 3, 121-139.

De Dominicis, S., Schultz, P.W. \& Bonaiuto, M. (2017). Protecting the environment for self-interested reasons: Altruism is not the only pathway to sustainability. Frontiers in Psychology, 8, 1065. doi: 10.3389/fpsyg.2017.01065.

Evans, L., Maio, G.R., Corner, A., Hodgetts, C.J., Ahmed, S. \&Hahn, U. (2013). Self-interest and pro-environmental behaviour. Nature Climate Change, 3, 122-125. doi: 10.1038/ nclimate1662.

Grouzet, F.M., Kasser, T., Ahuvia, A. C., Fernández Dols, J.M., Kim, Y., Lau, S.L., Ryan, R.M., Saunders, S.A., Schmuck, P. \& Sheldon, K.M. (2005). The structure of goal contents across 15 cultures. Journal of Personality and Social Psychology, 89, 800-816.

Knez, I. (2013). How concerned, afraid and hopeful are we? Effects of egoism and altruism on climate change related issues. Psychology, 4, 744-752. doi:10.4236/ psych.2013.410106.

Knez, I. (2016). Is climate change a moral issue? Effects of egoism and altruism on pro-environmental behavior. Current Urban Studies, 4, 157-174. doi: 10.4236/ cus.2016.42012.

Levy, A., Orion, N. \& Leshem, Y. (2016). Variables that influence the environmental behavior of adults. Environmental Education Research, 24(3), 1-19, doi:10.1080/13504622.2016.12 71865.

Nisbet, E.K.L. \& Gick, M.L. (2008). Can Health Psychology Help the Planet? Applying Theory 
and Models of Health Behaviour to Environmental Actions. Ottawa: Carleton University, Canadian Psychological Association.

Schwartz, S.H. (1992). Universals in the content and structure of values: Theoretical advances and empirical tests in 20 countries. In M. Zanna (Ed.), Advances in Experimental Psychology (Vol. 25). Orlando, FL: Academic Press. pp. 1-65. doi:10.1016/s00652601(08)60281-6.

Schwartz, D., Bruine de Bruin, W., Fischhoff, B. \& Lave, L. (2015). Advertising energy saving programs: the potential environmental cost of emphasizing monetary savings. Journal of Experimental Psychology: Applied, 21, 158-166. doi: 10.1037/xap0000042.

Thøgersen, J. \& Crompton, T. (2009). Simple and painless? The limitations of spillover in environmental campaigning. Journal of Consumer Policy, 32, 141-163.

UNEP (United Nations Environment Programme). (2020a). Science points to causes of COVID-19. Retrieved from https://www.unenvironment.org/news-and-stories/story/ science-points-causes-covid-19, visited 22 June 2020.

UNEP (United Nations Environment Programme). (2000b). Six nature facts related to coronaviruses. Retrieved from https://www.unenvironment.org/newsand-stories/story/ six-nature-facts-related-to-coronaviruses, visited 22 June 2020. 
